\title{
Rule Induction in the credit risk management of Inventory financing based on rough set

\author{
Zhigang Chen ${ }^{1, a^{*}}$, Yan $\mathrm{Li}^{1, \mathrm{~b}}$ and Hehua $\mathrm{Li}^{1, \mathrm{c}}$ \\ 'Shanghai Second Polytechnic University, Shanghai, China \\ azgchen@sspu.edu.cn, bliyan@sspu.edu.cn, chhli@sspu.edu.cn
}

Keywords: Rule induction; Rough set theory; Inventory financing; Credit risk

\begin{abstract}
The credit risk management in inventory financing is important for the commercial banks. The rule induction by rough set analysis is an effective tools for credit managers to evaluate the risk of bank loan. The purpose of this article is to propose a method to induce the decision rules of credit management in inventory financing by rough set analysis. By this method, we selected a case from a Chinese bank engaged in inventory financing, and conducted a rough set analysis on this case to gain an effective result on rules induction. These rules can help credit risk managers making the decisions in evaluating the default risk of bank loan in inventory financing.
\end{abstract}

\section{Introduction}

One of the challenges faced by small and medium enterprises is the financing of their operations. The small enterprises often have little in the way of fixed assets such as plants, machinery, equipment, trucks, and so on, which banks are willing to recognize as security for loans or leases. Thus, it can be difficult for them to borrow money except at prohibitive rates of interest. Lack of financial resources means that operational decisions can be severely constrained (Buzatcott et al, 2004). The asset-based financing is often used to overcome this problem and help to finance the small and medium enterprise's operations. Asset-based financing are loans that the bank lend to an enterprise with links to its assets such as inventory and accounts receivable.

Inventory financing, also called inventory loan, is a form of asset based lending, it is a short-term working capital loan secured by the inventory purchased. It can help improve enterprises' cash flow and provide funds to pay for business expenses, or to purchase additional inventory. As the inventory is converted into sales, the loan is gradually paid-off and new inventory is bought with a new loan, and the cycle starts all over again.

Inventory financing uses business inventory as collateral for loans. Inventory financing is often used by manufacturers of consumer products and by trading dealers, including dealers of steel, aluminum and car etc, because they have significant amounts of money invested in the inventory.

The inventory financing has developed rapidly in recent years in China. More than the CNB20 billion worth of inventory held by Chinese businesses is financed by bank loans with the goods pledged as security. But more than $40 \%$ of bank loans of inventory financing .for the steel-trading dealers ended up in default in China by 2012. Therefore the credit risk management of inventory-based loan is given much attentions by the Chinese lender. In order to solve this problem, the article proposes a rule induction approach for credit risk management of bank loans in inventory financing base on the rough set theory. These rules can help credit risk managers making the decisions in evaluating the default risk of bank loan in inventory financing.

The article is developed as follows: Firstly, a brief review of literature on inventory financing is presented. Secondly, the rough set theory and its rules induction in credit risk management is proposed and a case study of Chinese bank is followed. Finally, some remarks are concluded and future directions for the research are suggested in the last paragraph.

\section{Literature Reviews}

The research of inventory financing can be classified to three areas. The first one is the inventory financing decisions from the perspective of the enterprises which borrows moneys from the 
lenders(mostly banks); the second one is from the perspective of the logistics providers which provide the storage of the inventory and thus guarantee the liquidation of inventory to some extent. The third one is from the perspective of the financial provider or the banks.

The researches from the perspective of the enterprises mostly focus on production decision with the consideration of inventory financing. Wilson(1991) suggested that inventory financing is related to the classical optimization approach used to control the level of inventory as well as the tradeoff between setup costs and holding costs. Hill and Sartoris(1995) took the inventory financing as a short term financial management which affects the operating cash flows of the firm. Thus, it is an important factor when making operation decisions that affect cash inflows, cash outflows, liquidity, back-up liquidity as well as internal cash flows. Buzatcott and Zhang(2004) attempted to incorporate inventory financing into production decisions and model the available cash in each period as a function of inventory and liabilities that may be updated periodically according to the dynamics of the production activities.

The researches of inventory financing from the perspective of the logistics providers are often classified as one type of logistics finance. Lacroix and Varnangis(1996) argued that, through the comparison of the development of the logistics finance in the developed countries such as Europe and the United States, the innovation and integration of logistics and finance are of great significance to the developing countries in transition, to put forward specific proposals for developing countries to promote the logistics finance. Hofmann(2009) studied the qualitative analysis of the importance of inventory financing from the perspective of logistics service providers. Li, Wang and Feng(2010) analyzed the basic structure and content of logistics financial business and study on operational decision making and risk control decision making under capital constraints.

The researches from a financial service provider's perspective is concerned mostly with the commercial banks. Lasher(1997) proposed that when a company's current assets are used as security or as collateral for short term bank loans of inventory financing, a essential problem is the marketability of inventory in the hands of the banks. Unlike accounts receivables or back-up liquidity, inventory does not turn to cash by itself. It has to be sold. The closer the inventory is to being a commodity item, the easier it is for the banks to sell and the higher its collateral value. Compared to raw materials, commodity items such as iron ore used by a steel dealers are easier to resell than customized items such as specialty parts and components used to in factories. Customized components and parts may have only nominal resale value. Work-in-progress goods are frequently excluded from a collateral used in bank loans. Since work-in-progress goods require additional production activities to be converted to saleable merchandise, they have limited liquidation value. This is the reason why the bank loans by inventory financing is more often for raw materials or consumer goods than for work-in-progress goods.

Although there are many researches of inventory financing in the bank's perspective. But the research of credit risk management of inventory financing is scarce. This article makes research in this area, and proposes a rule induction approach for credit risk management of bank loans in inventory financing base on the rough set theory.

\section{Rough Set Theory}

The rough set theory was developed by Pawlak (1982). It has emerged as a major mathematical method in appraising and assessment. It can evaluate the importance (or weights) of particular attributes(or criteria) in relationships between objects. Moreover it is used to reduce all redundant attributes and get minimal subsets of attributes that ensure a satisfactory approximation of the classification made by decisions.

Information System and Indiscernibility Relation: Let $(U, A, F, V)$ be an information system, where $U$ is a non-empty set of finite objects(the universe).Universe describes all the research objects, denoted by $U=\left\{x_{1}, x_{2}, \ldots, x_{n}\right\} . A$ is the set of attributes belong to objects, denoted by $A=\left\{a_{1}, a_{2}, \ldots, a_{m}\right\} . \quad V$ is the set of values that attribute may take. $\mathrm{F}$ is the set of relations between attribute $a$ and object $\mathrm{x} . \quad \mathrm{f}(a, x)$ is the value of attribute $a$ for object $x$ in the universe $U$. 
The main concept of rough set theory is indiscernibility relation. Then $x_{i}$ and $x_{j}$ are indiscernible by the set of attributes $R$, if and only if $\mathrm{f}\left(a, x_{i}\right)=\mathrm{f}\left(a, x_{j}\right)$ for every $a \in P$

With any $\mathrm{P} \subseteq \mathrm{A}$, there is an associated equivalence relation denoted by

$\operatorname{IND}(\mathrm{P})=\left\{\left(\mathrm{x}_{\mathrm{i}}, \mathrm{x}_{\mathrm{j}}\right) \in \mathrm{U} \times \mathrm{U}, \mid \forall \mathrm{a} \in \mathrm{P}, \mathrm{f}\left(\mathrm{a}, \mathrm{x}_{\mathrm{i}}\right)=\mathrm{f}\left(\mathrm{a}, \mathrm{x}_{\mathrm{j}}\right\}\right.$

The relation $\operatorname{IND}(P)$ is called a indiscernibility relation. The partition of $\mathrm{U}$ is a family of all equivalence classes of $\operatorname{IND}(P)$ and is denoted by $U / I N D(P)$

Approximations and Positive Region: Suppose $\mathrm{P}$ is a non-empty subset of $\mathrm{A}$, the P-lower approximations of $\mathrm{X}$ are defined as

$\mathrm{P}_{*} \mathrm{X}=\{\mathrm{Y} \in \mathrm{U} / \mathrm{IND}(\mathrm{P}): \mathrm{Y} \subseteq \mathrm{X}\}$

$\mathrm{P}(\mathrm{X})$ is the largest union o the $\mathrm{P}$-elementary sets included in $\mathrm{X}$. it is also the positive region of $\mathrm{P}$ denoted by $\operatorname{pos}_{P}(\mathrm{X})$

The $\mathrm{P}$-upper approximation is the union of all equivalence classes in $U / I N D(P)$ which have non-empty intersection with the target set $X$

$\mathrm{P}_{*} \mathrm{X}=\{\mathrm{Y} \in \mathrm{U} / \mathrm{IND}(\mathrm{P}): \mathrm{Y} \cap \mathrm{X} \neq \emptyset\}$

Reduct and Core: A reduct is a subset of attributes $R \subseteq P$ such that the equivalence classes induced by the reduced attribute set $R$ are the same as the equivalence class structure induced by the full attribute set $P$

The set of attributes which is common to all reducts is called the core. The core is the set of attributes which is possessed by every legitimate reduct, The core is the set of necessary attributes.

Rule Induction: The information table can be classified as various categories based on a set of rules that describe the scope of the category. Rules induction is trying to find the minimal set of consistent rules that characterize a category. For a set of condition attributes $A=\left\{a_{1}, a_{2}, \ldots, a_{m}\right\}$ and a decision attribute $d$, a rule is defined as following. $\left(a_{1}=x_{1}\right) \wedge\left(a_{2}=x_{2}\right) \wedge \cdots \wedge\left(a_{m}=x_{m}\right) \rightarrow(d=y)$

This is a form typical of association rules, and the number of objects in $U$ which match the condition is called the support for the rule.

\section{Rule Induction in Inventory Financing}

The Crite ria of Credit Evaluation System: Due to the relatively higher default rate in inventory financing, the Chinese banks often set up a evaluation system, consisting of various criteria, to appraise the credit risk of a loan needed for approval. When a bank is approached by a client with an incremental inventory financing request, it is usually for the bank to consider the following factors:

(1)The classification of the inventory (i.e. finished goods, raw materials, work-in-process or specialty items)

(2)Whether the inventory(or part of it) is presold.

(3) Demand classification (known and steady, unknown but predictable, or unstable and unpredictable);

(4)The amount of current inventory as a percentage of the overall collateral pool.

(5)Appraised value of the inventory

(6)Seasonality of the business and industry cycle

(7)Whether the borrower is a manufacturer, distributor, or retailer.

(8)The financial leverage of the business as measured by the ratio of total liabilities to total assets.

We selected a Chinese bank, which was early engaged in inventory financing, as a case for analysis. The criteria of its evaluation system is shown below(Table 1) 
Table. 1 The criteria of evaluation system

\begin{tabular}{|c|c|}
\hline \multirow[t]{4}{*}{ Inventory } & $\begin{array}{l}a_{1} \text { : Classification of inventory (1-steel, 2-other metal3-wood 4-foodstuff } \\
5 \text {-commodities. Etc.) }\end{array}$ \\
\hline & $a_{2}$ : ratio of appraised value of the inventory to the total amount of loan \\
\hline & $a_{3}$ : Demand (1-growth, 2-steady, 3-depression 4-unpredictable) \\
\hline & $a_{4}:$ Whether the inventory is presold \\
\hline \multirow[t]{7}{*}{ Borrower } & $a_{5}:$ The total assets of borrower \\
\hline & $a_{6}:$ Number of employees $(1-[1-30], \quad 2-[31-100], 3-[100-500], 4->500)$ \\
\hline & $a_{7}$ : The ratio of total liabilities to total assets \\
\hline & $a_{8}:$ Ratio of quick assets to current liabilities \\
\hline & $a_{9}$ : The credit rating by the third party \\
\hline & $a_{10}$ : The ind ustries of the borrower (1-manufancture, 2-trading, 3-retail) \\
\hline & $a_{11}$ : Whether to guarantee for other one's debt (1-Yes, 2-No) \\
\hline \multirow{2}{*}{$\begin{array}{l}\text { Logistics } \\
\text { provider }\end{array}$} & $a_{12}$ : The credit rating of the logistics provider \\
\hline & $a_{13}$ : The guarantee of the logistics provider \\
\hline
\end{tabular}

Rough Set Analysis: The bank had recorded 97 loans in inventory financing. Thus we construct the information table with these records and the condition attributes $\left(a_{1}, a_{1}, \cdots a_{13}\right)$. The decision attribute is $d$, and $d=0$ if there is a default, otherwise $d=1$. we calculated the information table by the RSES which is a software specialized in the rough set theory. The result is shown below.

$\left(a_{1}=1\right) \wedge\left(a_{6}=1\right) \wedge\left(a_{10}=2\right) \rightarrow(d=0)$

$\left(a_{1}=1\right) \wedge\left(a_{6}=2\right) \wedge\left(a_{10}=2\right) \wedge\left(a_{11}=1\right) \rightarrow(d=0)$

$\left(a_{1}=3\right) \wedge\left(a_{4}=2\right) \wedge\left(a_{10}=3\right) \rightarrow(d=0)$

Rule Generation: By the rough set analysis, we can recognized at least three rules which end up with loan default.

Rule1: The inventory is steel, the borrower is a trading company, and the total number of employees is no more than 30 .

Rule2: The inventory is steel, the borrower is a trading company, they guarantee for other 's debt, and the total number of employees is between 31 and 100 .

Rule3: The inventory is wood, the inventory is not presold, and they are retail companies.

\section{Conclusion}

The credit risk management in inventory financing is important for the commercial banks. The rule induction by rough set analysis is an effective tools for credit managers to evaluate the risk of bank loan in inventory financing. This article proposed a method to induce the decision rules of credit management by rough set analysis. Because the samples are limited in this article, therefore it is necessary to do a further research with a large number of samples, thus to get more general rules in credit risk management of inventory financing.

\section{Acknowledgements}

The paper is aided by fund of discipline of management science(NO.XXKPY1606) from SSPU.

\section{References}

[1] John A. Buzacott, Rachel Q. Zhang: Inventory Management with Asset-Based Financing, Management Science,Vo1.50(2004)No.9,p.1274. 
[2] R. Lacroix and P. Varnangis: Using warehouse receipts in developing and transition economies, Finance \& Development, (1996)no. 9, p. 36.

[3] Y.X. Li, S.Y. Wang, and G.Z. Feng: Practical development and theoretic review of logistics finance - a new discipline direction, System Engineering theory \& Practice, vol.30(2010)no.1, p. 1.

[4] E. Hofmann: Inventory financing in supply chains: a logistics service provider-approach, International Journal of Physical Distribution and Logistics Management, vol.39 (2009)no.9,p.716.

[5] Wilson, J.M: Supplier credit in the economic order quantity model, International Journal of Operations \& Production Management, Vol. 11(1991) No. 9, p. 64.

[6] Altman, E.I., Brady, B., Resti, A. and Sironi, A: The link between default and recovery rates: theory, empirical evidence, and implications, Journal of Business, Vol. 78 (2005)No. 6, p. 2203.

[7] Angkinand, A.P: Banking regulation and the output cost of banking crises, Journal of International Financial Markets, Institutions \& Money, Vol. 19(2009) No. 2, p. 240

[8] Arcelus, F.J. and Srinivasan, G: Delay of payments vs price discounts for extraordinary purchases: the buyer's perspective, Engineering Cost and Production Economics, Vol. 19 (1990)No. 3, p. 273.

[9] Pawlak, Zdzisław: Rough sets, International Journal of Parallel Programming. Vol.11 (1982) No.5,p. 341

[10] Saaty, T.L: Multieriteria Decision - making: The Analytic Hierarchy Process, University of Pittsburgh, Pittsburgh, PA. (1988) 